\title{
TIEMPO Y EVOLUCIÓN
}

\section{TIME AND EVOLUTION}

\section{ESTEBAN VARGAS ${ }^{2}$}

\section{RESUMEN}

En este trabajo se intenta mostrar el problema del tiempo evolutivo en dos posibles concepciones. Por una parte, ya sea que la evolución se entienda como microevolución (cambio de frecuencias génicas) o macroevolución (especiación), el concepto de tiempo usado, en general, es el cronométrico, es decir, el tiempo que mide el reloj (meses, años, miles de años, etc.). Esto quiere decir que el tiempo es considerado como una variable independiente de los procesos biológicos. Sus fases temporales simplemente se suceden las unas a las otras. Pero, por otra parte, hay otra manera de entender el tiempo. Si la evolución es un proceso de una unidad evolutiva, entonces el cambio evolutivo consiste en la modulación de una serie de fases de una unidad que perdura. Es el tiempo cualitativo. Cada unidad evolutiva poseería su propio tiempo. Se revisa en el escrito algunas unidades evolutivas posibles (genes, poblaciones, especies, etc.) y cómo son concebidas temporalmente.

Palabras clave: Tiempo, evolución, unidad evolutiva, tiempo cronométrico, tiempo cualitativo.

\section{ABSTRACT}

In this paper we attempt to show the problem of evolutionary time in two possible conceptions. On the one hand, either evolution is understood as microevolution (change of gene frequencies) or as macroevolution (speciation), the concept of time used, gener-

${ }^{1}$ Este trabajo fue posible gracias a un proyecto FONDECYT de Postdoctorado № 3085042 llamado "El problema del tiempo biológico desde el horizonte de la filosofía de Zubiri".

${ }^{2}$ Profesor de Filosofía, Pontificia Universidad Católica de Valparaíso. Valparaíso, Chile, Email: esteban.vargas@ucv.cl 
ally, is chronometric, i.e. time measured by a clock (months, years, thousands of years, etc.). This means that time is considered as an independent variable of the biological processes and their temporal phases simply succeed each other. But on the other hand, there is another way to understand time. If evolution is an evolutionary unit process, then evolutionary change is the modulation of a series of phases of a unit that endures. It's a qualitative time. Each evolutionary unit would have its own time. We review in the paper some possible evolutionary units (genes, populations, species, etc.) and how they are conceived temporally. Finally, we analyze more precisely the problem of evolutionary time in a species as an evolutionary unit.

Keywords: Time, evolution, evolutionary unit, chronometric time, qualitative time.

Recibido: 27.12.10. Aceptado: 20.07.11.

S E PODRÍA DECIR, sin ánimo de ser preciso, que la evolución es el cambio de los seres vivos en el tiempo. Desde luego, habría que precisar dos problemas en esta definición. Por una parte, habría que atender a qué nivel o niveles de organización de los seres vivos hay que mirar para entender aquello que evoluciona. Éste es un problema que, en líneas generales, ha sido estudiado por biólogos y filósofos, aunque ya veremos hasta qué punto. Por otra parte, hay que meditar cuál es la concepción de "tiempo" que se tiene del proceso evolutivo. El tiempo en evolución es algo en que no se suele meditar. En este escrito pretendo mostrar el "problema" de la concepción del tiempo en evolución, su carácter problemático más que su posible solución. Para ello, en primer lugar, hay que atender brevemente a cómo se ha entendido el fenómeno evolutivo. Sin esto, cualquier especulación caería en el vacío. En segundo lugar, como el tiempo está relacionado con aquello que evoluciona, hay que meditar qué es lo que evoluciona. En tercer lugar, hay que revisar cuál o cuáles podrían ser las posibles unidades evolutivas. Sólo entonces, en cuarto lugar, podremos intentar comprender de mejor manera el problema del tiempo evolutivo.

\section{EL PROBLEMA DEL FENÓMENO EVOLUTIVO}

Los organismos cambian en el tiempo. Esto es lo que, en general, se llama desarrollo u ontogenia. Es algo fácil de notar. El problema se nos presenta cuando queremos pensar el cambio en términos evolutivos. ¿Hacia dónde tenemos que mirar para notar el cambio evolutivo? Veamos brevemente dos de las respuestas que se han dado sobre este problema: 
a) Ante todo, podría decirse que evolución es esencialmente especiación, es macroevolución. Así parecen entenderla Mahner y Bunge cuando nos dicen: "Para que un cambio cualitativo se considere evolutivo, debemos asumir finalmente que consiste en la emergencia de cosas de un nuevo tipo o especie (ontológica)" (2000: 348). Para que exista un cambio evolutivo deben emerger, entonces, propiedades nuevas que constituyan una nueva especie. Esto nos lleva a entender la evolución como un proceso de cambios a nivel de especie, distintos de los que ocurren en cada organismo individual (ontogenia). Esta conceptuación nos lleva a pensar que la biología evolutiva debe estudiar "el origen de las especies", es decir, qué es lo que ha ocurrido en la filogenia. Una definición semejante nos da Maynard Smith. "El estudio de la evolución se ocupa de cómo, a lo largo de la dilatada historia de vida en este planeta, se han adaptado los diferentes animales y plantas a diferentes condiciones, y a diferentes formas de vida en esas condiciones" (1984: 15). Pero esta concepción nos plantea el problema de si tenemos acceso perceptivo "inmediato" a la filogenia. ¿Hacia dónde tenemos que mirar para notar el cambio macroevolutivo? El cambio macroevolutivo, así entendido, no parece fruto de una inmediata descripción, nadie estuvo allí, por ejemplo, para ver cambiar los reptiles en aves. La macroevolución es, así, no un hecho, sino una teoría que debe explicar ciertos hechos. Una ciencia, que se precie de tal, no puede hacer de su "inmediato" objeto de estudio una teoría, por muy robusta que sea. No hay ciencia, por ejemplo, de las partículas elementales, sino, en rigor, de los hechos que "podrían" ser explicados con esa teoría de partículas. Es lo que ocurre también en la macroevolución. Por ello, tal estudio no pretende partir de la nada, sino de al menos dos hechos: el hallazgo de fósiles, y la unidad y diferencia de los seres vivos actuales, lo que llamo biodiversidad. Hay que tener en cuenta que, en rigor, no son "hechos" evolutivos, sino más bien "pistas" que nos llevan, con buena probabilidad, a una teoría macroevolutiva.

b) Por otra parte, podríamos considerar los cambios que ocurren entre generaciones de organismos y llamar a eso evolución (Futuyma, 2005: 2). Aquí, los cambios se miden en la variación de las frecuencias génicas, genotípicas o fenotípicas en una población. Es lo que constituye la microevolución. Estos cambios pueden observarse ya de una generación a otra y hacen de esta definición de evolución algo más fenoménico que la macroevolución. Aquí hay, entonces, dos posibilidades de mirar el fenómeno evolutivo que no son necesariamente excluyentes. 


\section{EL PROBLEMA DE LA UNIDAD EVOLUTIVA}

Entiendo por unidad evolutiva la entidad que notamos o, al menos, postulamos que cambia. Antes de desarrollar esto convendría hacer una pequeña aclaración. Tanto biólogos como filósofos han discutido largamente sobre cuál es la entidad que se selecciona. Es la llamada "unidad de selección". Convendría desarrollar esto brevemente para diferenciarlo de la unidad evolutiva. Ya desde Darwin se había sostenido que lo que se selecciona es el organismo como individuo. Si el individuo presenta un rasgo que le da una mayor ventaja en su supervivencia y reproducción dejará más descendientes que los otros individuos que no la presentan. Pero existen algunos rasgos que son difíciles de explicar por selección natural individual. Es el caso del altruismo, donde el individuo muere por los demás sin dejar descendencia. Si este rasgo es heredable, entonces los individuos altruistas tenderán a dejar menos descendencia que los egoístas. Así, en una población de altruistas bastarían unos cuantos egoístas para que con el tiempo aumenten su frecuencia poblacional por sobre la de los altruistas. ¿Cómo se conserva y selecciona, entonces, el altruismo? Una posible solución es que aquí la unidad de selección es el "grupo" y no el organismo. Sober, por ejemplo, intentó demostrar que lo que aumenta no es la eficacia individual altruista, sino la "eficacia promedio" de un grupo con predominio altruista en relación a otro con predominio egoísta. Así, nos dice: "Si los grupos compiten con otros grupos y si los grupos de altruistas lo hacen mejor que los grupos de individuos egoístas, entonces el altruismo puede evolucionar y mantenerse" (1996: 155). Pero existe otra solución. Podría interpretarse el altruismo como una selección de parentesco. Como se piensa que el altruismo es heredable y, por ello, determinable por genes, entonces, si un individuo es altruista, disminuirá su "eficacia individual" (pues, no deja descendientes), pero aumentará la "eficacia del gen" de la conducta altruista, ya que el individuo salvará a sus parientes que portan muy probablemente su mismo gen altruista. El resultado es que la frecuencia del gen del altruismo (y no los individuos) es el que aumenta su frecuencia y se selecciona. De éste y otros ejemplos surge el pensamiento de Dawkins. Para él, la unidad de selección es el gen (no el individuo), ya que éste es el que se beneficia y hereda en la evolución. El individuo no es más que el "vehículo" donde se transportan los genes. Así, Dawkins nos dice: "La unidad fundamental de selección, y por tanto del egoísmo, no es la especie ni el grupo, ni siquiera, estrictamente hablando, el individuo. Es el gen, la unidad de la herencia" (1985: 16). Posteriormente, para aclarar la relación entre individuo y gen 
en la selección natural, Hull (1980: 318) ha distinguido entre replicadores (la entidad que se replica) e interactores (la entidad que interactúa con el ambiente). Replicador sería, así, el gen y el interactor el individuo. Pero esta distinción funcional, como el mismo Hull y otros sostienen, puede extenderse a otras entidades. Replicador es el gen, pero también pueden ser considerados los cromosomas, el genoma entero en el caso de la reproducción asexual, etc. Interactores, por su parte, pueden considerarse los espermatozoides, los organismos, etc. Se establece, así, toda una jerarquía de interactores y replicadores, en el fondo, de unidades de selección, donde la evolución puede darse a distintos niveles.

He contado toda esta pequeña historia para mostrar que se ha discutido mucho el problema de la unidad de selección. Pero aquí nuestra meta no es definir cuál es la unidad que se selecciona, sino cuál es la "unidad evolutiva". La unidad de selección surge, en el fondo, por la competencia ya sea entre genes, individuos, grupos, etc. La unidad evolutiva, en cambio, es aquella unidad o entidad que "percibimos o postulamos" como cambiando en el tiempo. Ahora bien, aquí hay, en teoría, muchos candidatos a unidad evolutiva, los mismos que se consideraban para unidad de selección. Propongo, a modo de tesis, que para que una unidad sea evolutiva, es decir, cambie, debe presentar, al menos, tres caracteres:

1) Debe poseer cierta "unidad o entidad física" y no ser meramente conceptiva. La unidad debe imponerse perceptivamente y no ser construida lógicamente. Por ejemplo, la unidad "invertebrado" no es una propiedad positiva en una mariposa como sus alas. En el mismo caso están los grupos o poblaciones entendidos como meros "conjuntos", cuya unidad es más bien lógica que física. Si yo designo el conjunto "todos los libros amarillos que están en mi biblioteca", tal unidad es extrínseca a tales libros. Cuando este conjunto cambia, por ejemplo, cambiando algunos libros en mi biblioteca, tal conjunto no cambia por sí mismo, sino, en rigor, sólo por sus componentes individuales.

2) Ser heredable celularmente, es decir, pasar de padres a hijos por los procesos celulares (no, por ejemplo, por herencia cultural). Decíamos que la microevolución es un cambio entre generaciones. Una unidad que no pasara más allá de una generación sería un cambio ontogenético, pero no evolutivo. Pero entendamos aquí qué significa ser heredable. Siguiendo a Maynard Smith (1984: 47-48), hay que distinguir aquí dos sentidos de herencia. Por una parte, herencia es aquello "físico o material" que pasa de 
una generación a otra, es decir, de una célula a otra. No es claro cómo hay que pensar este pasar ni qué es lo que se pasa. Se dice que los genes pasan a la generación siguiente, pero no como estructuras materiales (ya que las moléculas se reemplazan tarde o temprano), sino como "información" contenida en la "secuencia" de nucleótidos. Además, habría que meditar también qué papel juega la herencia citoplasmática. No podemos entrar aquí en estos problemas. Lo que sí es claro es que, en este sentido, una mano, el altruismo, etc., no se heredan "materialmente" a la descendencia. Por otra parte, pueden tomarse rasgos de los padres e hijos y establecerse correlaciones estadísticas. Por ejemplo, se mide la altura de los padres y de los hijos y se ve qué correlación hay. Éste es básicamente el concepto de "heredabilidad" en el que se funda la genética. La altura, el color de ojos, etc., no son heredables materialmente, pero lo son como correlación estadística, aunque en diferentes grados. Ahora bien, una unidad evolutiva debe ser heredable en alguno de estos dos aspectos. Desde luego, ambos aspectos de la herencia se encuentran entrelazados, pues, el concepto de heredabilidad se basa en que tal correlación (lo único observable en este caso) se funde razonablemente en una herencia material. La heredabilidad, la correlación, se funda en la herencia material.

3) La unidad evolutiva debe "cambiar". Inspirándome en Aristóteles (1982) (Phys. 225 a20-b9), hay que distinguir aquí dos grandes tipos de cambio. Primero, la "transformación", el cambio sustancial (ser y dejar de ser). Segundo, el "despliegue procesual" en fases, un cambio que se manifiesta dentro de una misma unidad. Hay que averiguar qué tipo de cambio es la evolución. Ahora bien, como la unidad evolutiva cambia, este cambio lleva implícito un carácter temporal. Se trata de averiguar, entonces, en este escrito, qué tipo de tiempo está implícito en tal unidad que cambia. Para ello es necesario distinguir claramente dos tipos de tiempo.

a) Por una parte, hay que atender al tiempo "cronométrico" que es el tiempo entendido como "medida" del reloj. Como ya lo anunció Einstein (1984: 24-26), en este caso se trata de poner en relación de simultaneidad dos procesos físicos en tanto sucesivos. El primer proceso es el del reloj mismo. Un "buen" reloj debe poseer diversas fases sucesivas, pero éstas deben ser "equidistantes", es decir, que la "distancia temporal" entre sus fases debe ser la misma. El segundo proceso es el ente físico a medir. Lo que hacemos es poner en relación de simultaneidad las fases del proceso del reloj con las que así se establecen en el ente físico en cuestión. El ente físico posee ahora fases, pero en tanto establecidas extrínsecamente en su funcionalidad con 
el reloj. Lo medido entre fases es justamente el "tiempo cronométrico" (una hora, veinte minutos, etc.). Todo esto puede usarse para medir el tiempo de los procesos biológicos. Así, por ejemplo, podemos medir la llamada "edad cronológica" (cronométrica) de una persona en años, el tiempo de un lago como ecosistema, etc. Desde este concepto podemos pensar el tiempo de una unidad evolutiva. Así, podemos medir el tiempo cronométrico de una frecuencia génica de una población, el tiempo de una especie en millones de años, etc. El tiempo cronométrico evolutivo es, así, un tiempo que corre independiente de los procesos biológicos. Nos recuerda, un poco, al tiempo absoluto que concebía Newton.

b) Pero, por otra parte, es posible pensar el tiempo de otra manera. En un organismo, por ejemplo, las fases de su desarrollo están determinadas por el "proceso mismo" y no sólo en función de las fases de un reloj. Así, por ejemplo, si tenemos varias fases en el organismo (a una fase " $\mathrm{A}$ " le sigue una "B", a ésta una "C", etc.), la determinación de cada fase no se establece por su "distancia cronométrica" (horas, días, meses, etc.), sino por las determinadas "cualidades" que presenta la dinámica del sistema, por ejemplo, las fases del desarrollo de la vida humana como la infancia, adultez, vejez, etc. Estas fases constituyen la "edad biológica". La edad como fase temporal "cualitativa" merece un puesto en la concepción del tiempo ${ }^{3}$. Constituye un tiempo biológico "cualitativo" (en este caso, la edad biológica) que es "dependiente" del proceso de desarrollo del organismo. Ser joven o viejo no es una cualidad temporal que queda expresada por el tiempo del reloj. Ahora bien, esto mismo podría pensarse si ocurre en la unidad evolutiva. De ocurrir, constituiría un genuino tiempo evolutivo diferente al tiempo cronométrico. Así entonces, si la unidad evolutiva de cambio es de pura transformación (una cosa y después otra), su tiempo será puramente cronométrico. Pero si la unidad evolutiva es procesual con diversas fases, ésta poseería un tiempo cualitativo propio, distinto del tiempo del reloj. Convendría aclarar en este punto que ambos tipos de tiempo no son excluyentes. El tiempo cronométrico se puede aplicar a cualquier realidad física. Y los seres vivos son, ante todo, realidades físicas. El problema es que el número que expresa la medida temporal de la unidad biológica no expresa

${ }^{3}$ La edad como estructura temporal propiamente biológica ya ha sido levemente expresada por el filósofo español Zubiri (2008a: 254). Su trabajo ha sido profundamente inspirador para desarrollar una concepción del tiempo biológico distinta del tiempo cronométrico. He expresado esa concepción en Vargas (2009). 
nada sobre la dinámica intrínseca del proceso biológico. Por ello, si una unidad evolutiva puede expresar su cambio "sólo" en el tiempo cronométrico (meses, años, etc.), esto quiere decir que sus fases en tanto funcionales a las fases de un reloj son meramente extrínsecas, están desconectadas las unas de las otras. La unidad de una fase con otra es de mera yuxtaposición, sólo viene una "después de otra", que es el caso de un cambio puramente transformativo. Esto no quiere decir, repito, que el tiempo evolutivo por excelencia sea el tiempo cualitativo. Perfectamente la evolución podría ser un mero cambio extrínseco. Es justo lo que hay que averiguar. Para meditar esto, tenemos que empezar a pensar el tiempo evolutivo en algunas posibles unidades evolutivas. No está de más decir que no pretendo resolver este problema, sino más bien orientar su discusión.

\section{POSIBLES UNIDADES EVOLUTIVAS}

Existen muchos candidatos posibles a unidades evolutivas que no necesariamente deben ser excluyentes. Para meditar su carácter temporal habría que atender también a su posible unidad física y herencia, dado que su carácter temporal depende de estas características. Veamos ahora, brevemente, algunas posibles unidades evolutivas. Si existen otras el lector podrá sacar sus propias conclusiones sobre ellas.

1. Dawkins, como hemos visto, nos ha señalado que el "gen" es la unidad de selección. Pero habría que pensar aquí si es una unidad evolutiva. El gen es, ante todo, una unidad "funcional", es decir, es el "determinante" del fenotipo. Esto se sabía "antes" que se identificara el gen como un trozo de $\mathrm{ADN}$, lo que demuestra que tal función, al menos como idea, posee una mayor inmediatez. Pero podemos considerarlo, en cierta forma, como una unidad física. Es, además, algo heredable, en sentido material. No entremos en estos problemas que no nos incumben. El problema es la concepción latente de tiempo que subyace aquí. El gen como unidad física no es una unidad procesual, no nos ofrece diversas fases de cambio ("A", "B", "C", etc.). El gen, o es el mismo o es otro. Su cambio es sólo transformación por mutación. Como hemos visto, la transformación es un tipo de cambio, pero uno muy extrínseco. También un perro, por ejemplo, cuando muere se transforma, pero ¿es esto evolución? Habría que meditarlo. Ahora bien, hay otra posibilidad de pensar esto: tomar el cambio en términos de "frecuencia poblacional" de genes. Lo que cambia no es el gen, sino su frecuencia. Aquí hay que destacar que el tiempo de los cambios de frecuencia sólo es expresable como tiempo cronométrico. Volveremos sobre esto más abajo. 
2. Otra unidad posible son las partes o momentos individuales del organismo, ya sean sus fenotipos o funciones. Así, se habla de la evolución del cerebro, del sistema digestivo, del sistema respiratorio, etc. Pero estas partes o momentos, "individualmente considerados", claramente no evolucionan en y por sí mismos. No existe un cerebro individual, por ejemplo, que "por sí solo" vaya pasando de generación en generación. Sin embargo, podrían considerarse tales partes como frecuencias fenotípicas. Así, por ejemplo, puede medirse las variaciones de frecuencia del color de ojos azules. A este cambio en las frecuencias se le aplica lo que ya vimos en el caso de las frecuencias génicas, es decir, que se trata de un tiempo cronométrico como tendremos que ver.

3. Una tercera unidad posible es el organismo entero. Pero, los cambios en el organismo, decíamos, constituyen el desarrollo y no la evolución. Los organismos "enteros" no pasan a la descendencia. Un caso problemático son los organismos unicelulares. Cuando la célula madre se divide, las dos células hijas, ¿son organismos individuales distintos de la madre? ¿Dónde termina el desarrollo de un organismo unicelular? No es claro esto en los organismos unicelulares. Lo que sí es claro, por definición, es que evolución no es el cambio de los organismos pluricelulares enteros.

4. Una cuarta posibilidad es la especie. ¿Qué tipo de realidad posee? ¿Es heredable? Para responder estas preguntas habría que ver cómo se ha entendido una especie. Veamos algunos conceptos. Especie podría significar lo "común" a muchos individuos. Es el concepto "tipológico" de especie. El problema de este concepto es que lo expresado en él "no puede evolucionar". Bajo el influjo de Darwin, Ernst Mayr propuso un nuevo concepto de especie a partir del aislamiento reproductivo de los organismos. Así, nos dice que "según este concepto [biológico], una especie es un conjunto de poblaciones naturales capaces de cruzarse unas con otras, y [que está] aislado reproductivamente (genéticamente) de otros grupos similares por barreras fisiológicas o de comportamiento" (1998: 147). Este concepto "biológico" de especie intenta expresar algo real y no meramente lógico. Es el cruce con descendencia de los organismos (y no los aspectos que se consideren más importantes entre las propiedades comunes) lo que decide si dos organismos pertenecen a una misma especie. Ahora bien, de este concepto de Mayr se han desprendido dos interesantes interpretaciones de lo que es especie que me gustaría destacar. Por una parte, Zubiri define la especie como "el grupo de notas genéticamente transmisibles y perdurables por interfecundidad" (2008b: 243). Para él, la especie es un sistema de genes que constituyen algunas notas o momentos del organismo individual. La especie es, así, un momento del organismo que es común y heredable. Aunque 
sólo existiera un organismo, éste sería "especial" en el sentido de poseer un momento de especie. Pero hay, por otra parte, una segunda opción. Como la especie es concebida como un "conjunto de poblaciones" ligadas por flujo génico (concepto de "población reproductora"), tal conjunto es considerado, por ejemplo, por Sober (1996) como un "individuo", al modo como lo es un organismo. Ello ocurre porque, para él, un individuo se define como una entidad que posee partes que interaccionan "causalmente". Esto es precisamente lo que él cree que ocurre en una especie como población reproductora. Sober agrega además que hay que entender el individuo no sólo sincrónicamente, sino diacrónicamente. Así como el organismo varía en el tiempo y sigue siendo el mismo individuo, así también varía la especie sin perder su individualidad. Por ello, define a las especies como "entidades históricas" (1996: 243).

Debemos estudiar ahora estos conceptos de especie como unidad evolutiva, según las características que hemos dado antes. Ante todo, es claro que el concepto "tipológico" de especie no es una unidad física y, por ello, es atemporal. Es este concepto el que impidió pensar en términos evolutivos. Los otros dos conceptos de especie son más interesantes para pensarlos como unidad evolutiva. Zubiri, veíamos, entiende la especie como un momento genético del organismo que es heredable. Este concepto posee también sus problemas. Ante todo, ¿cuál es su realidad física? ¿Cómo se distingue la secuencia genética que forma la especie de la que no la es? El gen del color de ojos azules, por ejemplo, es heredable, pero no forma parte de la especie humana, pues no todos poseen los ojos azules. Aquí hay que apelar a los genes "comunes" o esquema común de los organismos. Pero esto "común" es algo extrínseco a cada organismo y no es algo que cumpla una función física dentro de él. No obstante ello, pienso que éste es uno de los buenos candidatos para ser unidad evolutiva. Volveré sobre ello más abajo. El otro concepto entiende la especie como "individuo". Aquí es dudoso si un "conjunto" de poblaciones entendidas sincrónica y diacrónicamente puedan constituir un "individuo". La especie entendida como conjunto, más que un individuo, parece una unidad "aditiva" de poblaciones, aunque estén interrelacionadas. Ante todo, no parece que sincrónicamente el flujo génico constituya una relación causal que constituya un individuo. Tal flujo no es constante ni está constituyendo operativamente ni a la población ni a la especie como un "todo". Esto es muy distinto, por ejemplo, a lo que ocurre en un organismo pluricelular donde sus células están relacionadas "operativamente" a través de linfocitos, hormonas, etc. Lo mismo se podría decir de su aspecto diacrónico. La especie como unidad aditiva de poblaciones reproductoras no cambia en el tiempo en tanto "unidad", ni siquiera 
considerado esto como tiempo cronométrico. Los que cambian, en rigor, son sus componentes, los organismos.

5. Finalmente, podríamos pensar en la población. Según Mahner y Bunge hay que distinguir tres sentidos del término población: "Puede significar (a) una población estadística, es decir, una mera colección de individuos [...] o (b) un agregado (o montón) de individuos [...] o (c) un sistema de individuos, como en el caso de las comunidades reproductivas o las sociedades animales" (2000: 180). El sentido de "población estadística" es interesante, sobre todo cuando los organismos que constituyen una población poseen características similares. Así, es muy común pensar que la evolución, como ya vimos, es un cambio en la frecuencia de genes o fenotipos poblacionales. Pero entendido así sin más, un cambio de frecuencia es un cambio donde la población es entendida aquí como un mero "conjunto lógico". Esto es lo mismo que sucedía con el concepto "tipológico" de especie. Los organismos en este concepto tipológico forman una especie por sus meros caracteres comunes. El mismo error se comete con la idea de población estadística o, dicho sea de paso, con cualquier grupo superior a la población que se entienda como mero "conjunto". ¿Qué concepción de tiempo hay en la población estadística? Como no posee una unidad física propia, la población estadística no cambia en tanto "población". La población cambia sólo en tanto que sus individuos cambian en sus relaciones o frecuencias. Por ello, no posee un tiempo cualitativo propio. Su único tipo de tiempo, visto desde los individuos, es el cronométrico. El tiempo de la frecuencia de genes o fenotipos son las horas, minutos, etc., en que unos individuos están relacionados con otros. La frecuencia génica o fenotípica no es, por ello, "de" la población, sino "en" la población. En un segundo sentido, la población como "agregado" es una cierta unidad física, pero en rigor no lo es, no actúa como unidad, como "población sistémica". Es una unidad aditiva resultado de la mera sumatoria de los individuos, algo así como una mezcla en física. No posee, por ello, un tiempo cualitativo propio, sino el de sus individuos. En un tercer sentido, la población podría entenderse como un "sistema". Esto haría de él una entidad física y una posible unidad evolutiva. Ahora bien, aquí hay, a su vez, dos sentidos que hay que diferenciar. Por una parte, la población puede ser un sistema como un conjunto de organismos que intercambian flujo génico como en la llamada "población o comunidad reproductiva" que hemos visto antes. Así, se suele definir la población como "un grupo de organismos de una especie que ocupan un espacio dado en un momento específico" (Krebs, 1985: 147). Aquí hay que entender la especie no como un concepto tipológico, sino biológico, al modo de Mayr. Es lo que distingue precisamente la población reproductora de la estadística. 
Sin embargo, el hecho de que los organismos de la población estén relacionados por un flujo génico, ya sea en el pasado, como potencialmente en el futuro, no hace de esa población un "sistema", tal como ocurre en el caso de la especie como individuo. Para que sea un sistema, la población debe mostrar propiedades emergentes distintas de las propiedades de cada uno de sus organismos. El flujo génico, veíamos antes, no es causal, no hace surgir propiedades poblacionales, sino individuales. Pero hay un segundo sentido de población como sistema. Es el caso, por ejemplo, de las sociedades animales. Se podría llamar a esto la población como "sistema social". En este caso, los organismos están relacionados no por un mero flujo génico, sino, a mi juicio, por "comunicación". Esta comunicación puede ser, ante todo, química, por las llamadas feromonas. Esto origina un "esbozo" de población social. Pero la comunicación se produce principalmente por comunicación visual y auditiva en las sociedades animales. Si esto es cierto, habría que repensar la clásica definición de población dada más arriba. La población, en primer lugar, no es un "grupo" de organismos, sino un "sistema"; en segundo lugar, no es necesario que sean de la misma especie. Lo que sucede es que al ser de la misma especie (por flujo génico) hay más posibilidades de comunicación. Lo mismo sucede con la exigencia de ocupar un mismo espacio y tiempo (sincrónico). Si los organismos cohabitan en un mismo "espacio-tiempo", tendrán más posibilidades de comunicación. Ser de la misma especie y cohabitar en un mismo espacio-tiempo son condiciones para poder ser población social. Pero no son lo que la define. No está de más decir que introduzco esta idea a modo de tesis. Ahora bien, ¿qué concepción de tiempo hay en la población como sistema? En el caso de la población reproductora, como ella no es un sistema, no posee un proceso propio y su tiempo es el de sus individuos y sus relaciones. Pero sería digno de pensarse el tiempo en la población como sistema social. El caso más importante es la historia humana. En el proceso histórico encontramos fases que llamamos, al igual que en el organismo, edades ${ }^{4}$. Así, se habla de la Edad Media, la Edad de Piedra, etc. Habría que pensar si se da esto, de algún modo, en las llamadas sociedades animales. Ahora bien, sea esto o no verdad, hay que señalar que la población como sistema social no es la unidad evolutiva que buscamos. Este tipo de población tendría, tal vez, una unidad física y una unidad procesual con un tiempo cualitativo. Pero su herencia

\footnotetext{
${ }^{4}$ Zubiri ha intentado pensar la edad como fase de un proceso histórico (2006: 161). Es lo que llama "edad histórica". Tales edades no son determinadas por el reloj, sino por criterios históricos que buscan determinar las cualidades o fases intrínsecas del proceso.
} 
no es celular, sino cultural, en un amplio sentido de la palabra. No podemos desarrollar este tema aquí.

\section{EL PROBLEMA DEL TIEMPO EVOLUTIVO}

Veíamos antes los principales candidatos a unidades evolutivas analizando tres propiedades: su unidad física, su carácter heredable de una célula a otra y su carácter cambiante. Convendría repensar todo esto en función del problema del tiempo evolutivo que intentamos comprender. Recordemos que hemos visto dos tipos de tiempo: un tiempo cronométrico donde las fases son puramente sucesivas y un tiempo cualitativo biológico donde las fases están determinadas por la dinámica del proceso. Ahora bien, de entre las posibles unidades evolutivas que hemos visto, algunas son meramente lógicas o aditivas y no cambian en tanto tales. Es el caso de la población entendida como mero "conjunto o agregado". Hay otros casos que son unidades que no se heredan celularmente como los organismos pluricelulares como un todo y las poblaciones como sistema social. Veíamos también que hay unidades cuyas frecuencias génicas y fenotípicas (que estudia la microevolución) deben ser consideradas sólo en el tiempo cronométrico. De ningún modo hay que descartar que el tiempo evolutivo sea por ello puramente cronométrico. Finalmente, vimos el caso de las especies. La especiación (el cambio a nivel de especies) es lo que ha estudiado la macroevolución. Recordemos que hay dos tipos de especie que podrían ser unidades físicas evolutivas; la especie como individuo y la especie como momento del organismo. He señalado que la especie como "conjunto de poblaciones reproductoras" no es un individuo. He visto también los inconvenientes de la especie como momento del organismo. Pero, independiente de estas dos concepciones, parece que la especie podría ser un buen candidato a unidad evolutiva. Por ello tenemos que preguntarnos con más detalle ahora, ¿cómo se concibe el tiempo en las especies?

De toda especie podemos decir que posee una cierta antigüedad en años. Es la especie en el tiempo cronométrico. Pero intentemos meditarla, si es posible, desde un concepto de tiempo cualitativo biológico. Normalmente, se habla, por ejemplo, de especies que son más "antiguas" que otras, de organismos que son una especie de fósiles vivientes, etc. Aquí tenemos que preguntarnos: ¿hay especies jóvenes o adultas como una cualidad temporal de ellas mismas, sin apelar a su antigüedad en función del reloj? ¿Existe un tipo de "edad" en las especies? ¿Es posible pensar la especiación como un proceso que posee diversas fases? En general, se suele pensar la antigüedad 
de las especies sólo en términos del "tiempo cronométrico". Sin embargo, esto no es tan claro. Los paleontólogos, como Eldredge y Gould, nos hablan de diversos ritmos evolutivos de las especies. Nos dicen que, en general, las especies poseen una fase de cambios bruscos al comienzo y luego una fase de estabilidad. ¿Podría interpretarse esto como una dinámica temporal propia de las especies? ¿Podría haber, al menos, dos fases o edades en las especies, una fase juvenil y luego una de madurez? Para entender esto, convendría revisar brevemente la teoría del "equilibrio puntuado" de Gould y Eldredge. Gould nos la explica así: "El equilibrio 'puntuado' es una teoría sobre el proceso de formación de especies a partir de otras ya existentes (o especiación) en el tiempo geológico. Como tal, trata del ritmo y del modo de la evolución" (1982: 121). Esta teoría, entonces, pretende explicar la especiación en el tiempo geológico repensando su ritmo y modo en cierta oposición a como habían sido pensados en la teoría sintética de la evolución. Concentrémonos en el ritmo de especiación, que es el tema donde comparece mejor el problema del tiempo. La teoría sintética de la evolución sostenía, fundada en Darwin, un "gradualismo filogenético", es decir, que la especiación es gradual, a diferencia de lo que propone el "equilibrio puntuado". Estos dos modelos los podemos apreciar en la Fig. 1.

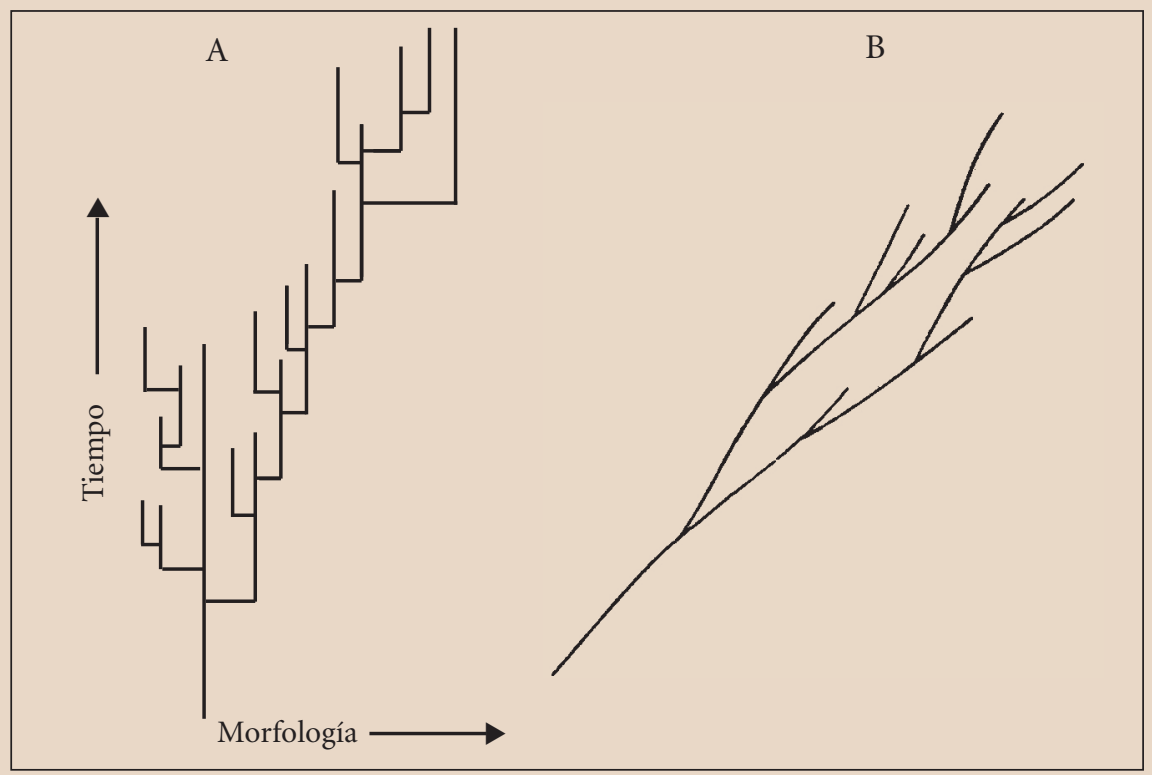

Figura 1. Una tendencia evolutiva según el equilibrio "puntuado" (A) y según el gradualismo filogenético (B) (según Gould, 1982). 
Este gráfico nos muestra los tres aspectos que postulábamos de la unidad evolutiva. En primer lugar, la "línea" representa la unidad física que evoluciona. En este caso parece ser la especie. Las unidades de selección pueden ser muchas, pero, en este gráfico, se nos muestra una sola unidad física. En segundo lugar, la línea "continua" representa la herencia de la unidad evolutiva de padres a hijos. Habría que meditar si, en rigor, debería ser "discreta". En tercer lugar, hay que notar que el tiempo geológico, para ambos modelos, corre "independientemente" de los cambios morfológicos de las especies. Este tiempo geológico no es otra cosa que un tiempo cronométrico. Habría que pensar si estos dos modelos pueden expresarse temporalmente de otra manera. Meditemos ahora algunas diferencias entre ambos modelos. En la figura $1 \mathrm{~B}$, como el cambio morfológico es gradual, no hay forma de diferenciar exactamente una especie de otra más que cuando los cambios se hacen evidentes luego de un largo tiempo geológico. Así, nos dice Eldredge:

La evolución produce un cambio continuo, una transformación continua de las poblaciones, y los taxonomistas no hacen más que subdividir abstractamente este flujo continuo de manera arbitraria y hasta caprichosa. En teoría, para el taxonomista neodarwinista, si una estirpe cambia de un estadio A hacia un estadio B de tal modo que muestras de $\mathrm{A}$ y de $\mathrm{B}$ parecen tan diferentes como dos especies contemporáneas, pongamos el león y el tigre por ejemplo, entonces tiene derecho a delimitar en la estirpe evolutiva dos especies A y B (1983: 798).

En este modelo (Fig. 1 B), la unidad evolutiva, se nos dice, posee una serie de estadios o fases, pero, por lo que se muestra en el gráfico, tales estadios sólo parecen establecerse en función de ciertas diferencias morfológicas establecidas en un tiempo cronométrico y no por modulaciones intrínsecas. Por contrapartida, en la Fig. 1 A, se nos muestra un período geológico corto de cambios morfológicos bruscos (línea horizontal) seguido de una gran estabilidad morfológica en el tiempo geológico (línea vertical). El mismo Eldredge nos lo explica así: "Esta evolución por equilibrios intermitentes [puntuados] sostiene convincentemente la idea de que cada especie es una entidad individual, delimitada en el tiempo por un origen, una historia y un final" (1983: 799). En este concepto (Fig. 1 A) se nos dice que la especie es una "entidad individual" que tiene un origen, una historia y un final, tal como ocurre con los organismos. Dicho así sin más, pareciera que hemos encontrado aquí una concepción de especie como si fuera un proceso biológico con diversas fases y, por ello, con un tiempo cualitativo. Pero no es 
esto lo que muestra el gráfico ni lo que parecen pensar, en el fondo, esos autores. La especie se concibe como siendo la "misma" (línea vertical) o como siendo abruptamente "otra" (línea horizontal). Aquí, el cambio evolutivo no es la modulación de fases de un proceso (un cambio cualitativo "A", "B", "C", etc.), sino de "trans-formación" en otra especie. O se es un tipo de especie o se es otro. Esto es lo que no ocurre en un organismo individual. Por ello, en los períodos de estabilidad (los más largos), lo único que cambia es el tiempo cronométrico. La especie en tanto especie es aquí extrañamente un individuo sin cambio, es una unidad evolutiva sin cambio. Algo semejante es lo que sucede con el gen de Dawkins. Pero hay otras alternativas a lo que plantean, de algún modo, Gould y Eldredge. Margalef (1998: 173), pensando en estas mismas características de la especiación, sostenía que la evolución consiste en una acumulación de "información", tal como ocurre en un organismo individual y en un ecosistema. Esto permitiría establecer diversas fases cualitativas. Pero la especie es entendida aquí, no por su mera estructura, sino por su información desde un punto de vista termodinámico. Es la especie como entidad física, justo el punto de vista de un ecólogo de ecosistemas. Pero, sea esto como fuere, para pensar el tiempo evolutivo tenemos que meditar, ante todo, cómo se perciben las especies. Voy a intentar esbozar aquí la dirección donde, tal vez, habría que dirigir la mirada en un enfoque fenomenológico del problema.

Para "ver" la especie hay que tener presente a los organismos actuales o fósiles y mirarlos por el lado en que sus "estructuras" son heredables. Cuando decimos, por ejemplo, que el cerebro evoluciona o que varía la frecuencia de un color de ojos, se trata de mirar estos cambios por el lado en que son precisamente un momento (no una parte aislada) de una "estructura heredable". El cerebro o el ojo, como órganos "individuales", son un momento del organismo individual que nacen y mueren con él. Sólo mirado como momento estructural heredable constituyen un momento de la especie. Una estructura en el organismo que no fuera heredable (una verruga, un moretón, etc.) no formaría parte de su momento "especial". Especie es, así, un momento estructural del organismo, sin ser todo el organismo. En esto Zubiri tenía cierta razón. El problema es definir la especie por su carácter común, darle una "clausura" rigurosa al momento estructural heredable frente a otros taxones como familia, clase, etc. El carácter común no es algo puramente convencional, pero tampoco es algo meramente intrínseco. El ser común no es una propiedad que cumple una función dentro del organismo como el tener alas. Más bien, es una "consecuencia" de la heredabilidad de los caracteres que permite, con cierta convencionalidad, formar 
todos los conceptos taxonómicos. Los cambios morfológicos (macroevolución) y de frecuencia (microevolución) se refieren, ambos, al momento "especial" del organismo. Es un problema que hay que seguir meditando.

Pensemos ahora el carácter temporal de la especie. Cuando decimos, por ejemplo, que el erizo de mar es más "antiguo" que el hombre, no estamos suponiendo esa antigüedad considerando al erizo de mar y al hombre como "organismos individuales". Ambos son organismos actuales, ninguno de ellos, individualmente considerado, es más antiguo que el otro. Lo que queremos decir es que la "estructura especial" del erizo de mar es más antigua que la del hombre. Desde luego, se piensa, ante todo, tal antigüedad en años. Pero cabría pensar en la posibilidad de que las especies tengan "edad". Esto no significa que una especie sea una suerte de gigantesco "organismo individual" ni que sea un "sujeto" bajo los cambios, sino de que la especie sea un "proceso", un sistema que "perdure cambiando", con diversas fases que determinen un "tiempo propio para cada especie". Creo que la especie, tal como la hemos entendido, es la mejor apuesta para un tiempo evolutivo cualitativo. Sin embargo, ni aun pensado así, parece que la especiación sea un proceso de modulación de fases. Si ello no ocurre, la evolución sólo estudiaría cambios "especiales" puramente sucesivos en el tiempo cronométrico, como la medición de las frecuencias en microevolución y de los cambios morfológicos en macroevolución. Si es así, la evolución, tal vez, no tiene mucho sentido como proceso "propiamente biológico" y no meramente físico (sucesivo). Ha sostenido Dobzhansky, en el título de un artículo (1973), que "nada en biología tiene sentido sino a la luz de la evolución" Pero, quizá, la misma evolución, "como teoría del cambio", posea poco sentido biológico y no sea otra cosa que el cambio de los seres vivos, pero considerados sólo por el momento en que son "una mera sucesión física", es decir, una cosa después de otra. Es algo que habría que seguir meditando.

\section{REFERENCIAS}

Aristóteles (1982). Física. Madrid: Gredos.

Dawkins, R. (1985). El gen egoísta. Barcelona: Salvat.

Dobzhansky, T. (1973). "Nothing in Biology Makes Sense Except in the Light of Evolution”. American Biology Teacher 35, 125-129.

Einstein, A. (1984). Sobre la teoría de la relatividad especial y general. Madrid: Alianza.

Eldredge, N. (1983). “La macroevolución”. Mundo Científico, № 16, 792-803.

Futuyma, D. (2005). Evolution. Sunderland, MA: Sinauer Associates, Inc. 
Gould, S. (1982). "El equilibrio puntuado y el enfoque jerárquico de la macroevolución". Revista de Occidente 18-19, 121-48.

Hull, D. (1980). "Individuality and Selection". Annual Review of Ecology and Systematics Vol. 11, 311-332.

Krebs, Ch. (1985). Ecología. México: Harla.

Mahner, M., Bunge, M. (2000). Fundamentos de biofilosofía. México: Siglo XXI.

Margalef, R. (1998). "Progreso: una valoración subjetiva entusiasta de casi la mitad de los cambios en los sistemas vivos”, en J. Wagensberg y J. Agusti (eds.), El progreso. Barcelona: Tusquets.

Maynard Smith, J. (1984). La teoría de la evolución. Madrid: Blume.

Mayr, E. (1998). Así es la biología. Madrid: Debate.

Sober, E. (1996). Filosofía de la biología. Madrid: Alianza.

Vargas, E. (2009). "El problema del tiempo biológico en Zubiri”. Philosophica, Vol. 35, 229-258.

Zubiri, X. (2006). Tres dimensiones del ser humano: Individual, social, histórica. Madrid: Alianza.

(2008a). Espacio, tiempo, materia ( $2^{\text {a }}$ ed.), Madrid: Alianza. (2008b) [1962]. Sobre la esencia ( $2^{\mathrm{a}} \mathrm{ed}$.). Madrid: Alianza. 